\title{
O PAPEL DA ACTUAL EDUCACIÓN ESCOLAR NA CONFORMACIÓN DO SUXEITO POSMODERNO ${ }^{1}$
}

\author{
Alejandro Villamor Iglesias \\ Universidade de Santiago de Compostela \\ bttp://dx.doi.org/10.15304/ag.37.2.4269
}

\section{Resumen}

El objeto de este artículo es la construcción del sujeto en la Posmodernidad. A partir de la comprensión del sujeto posmoderno como un constructo elaborado mediante prácticas discursivas, en el sentido foucaultiano, que se propagan y normalizan en diferentes espacios, se defenderá que la función de la escuela está en nuestros días amalgamada a los intereses del sistema capitalista. Así, tanto el modo en que nuestra sociedad torna en "sociedad de control" como la manera en que esta se legitima y perpetúa a través de la escuela, nos llevarán a la conclusión de que la formación intelectual y moral, lejos de ser el fin último de esta, es empleada como medio interesado por la primera.

Palabras clave: posmodernidad, capitalismo, escuela, subjetivación, Foucault, LOMCE.

\begin{abstract}
The configuration of the subject in the Postmodernity is the object of this paper. From the understanding of the postmodern subject as a construct elaborated by discursive practices, in foucaultian sense, which are propagated and normalized in different places, it will be held that the function of the school is currently linked to the interests of the capitalism system. Thus, both the way in which our society becomes a "society of control" and the way in which it is legitimized and perpetuated through the school, will lead us to the conclusion that intellectual and moral formation, far from to be the ultimate goal of it, is used as an interested instrument by the first one.
\end{abstract}

Keywords: postmodernity, capitalism, school, subjectivation, Foucault, LOMCE.

Recibido: 09/09/2017. Aceptado: 20/12/2017.

${ }^{1}$ Quero expresar o meu agradecemento a Juan Carlos Pardo, así como aos revisores anónimos da revista polas melloras propiciadas. 


\section{Introdución}

Froito da sospeita de que a problemática educativa á que nos atemos nos nosos días ten como razón de ser a configuración do suxeito en xeral, e do adolescente en particular, como meras engrenaxes do binomio produción-consumo, o presente traballo procura cotexar dito sentimento. Para levar a cabo esta empresa, o apartado 2 amosará de que xeito a sociedade neoliberal actual, incluída no seo da Posmodernidade, configura aos suxeitos baixo "sistemas de control" interiorizados por eles mesmos. Así, este punto centrarase nunha análise estrutural do suxeito posmoderno que reduciremos a dous elementos fundamentais: o paso da sociedade disciplinaria, tal e como a concibe Michel Foucault, á sociedade de control descrita por Gilles Deleuze (2006, 277-286), así como a capacidade performativa dos mass media. No terceiro apartado comezarase por describir brevemente o transcurso que seguiu a escola dende o seu nacemento no século XIX ata a actualidade, pasando pola escola comprensiva cimentada sobre o Estado de Benestar e o seu ulterior derrubamento coas reformas neoliberais. $\mathrm{O}$ obxectivo deste será, pois, ofrecer unha breve perspectiva da conformación do suxeito posmoderno dende o prisma histórico-empírico ofrecido pola evolución do sistema educativo dende a Modernidade ata a actualidade. A modo de exemplo paradigmático, este apartado concluirá mostrando as principais claves curriculares (competencias, contidos curriculares e criterios de avaliación) da LOMCE española en tanto dispositivos cos que a escola conforma a subxectividade do actual alumnado. Deste xeito, o nivel de análise centrarase neste momento na dimensión político-institucional coa que se configura aos suxeitos, a través do espazo escolar, nos nosos días. No último punto do traballo realizaranse unhas valoracións conclusivas.

\section{O suxeito da Posmodernidade}

\subsection{O paso da sociedade disciplinaria á sociedade de control}

Foi Michel Foucault quen mostrou que "el Siglo de las Luces fue también el de las disciplinas” (Fernández Enguita, 1990, 158). Foi este quen ollou por vez primeira a utilidade que o estudio xenealóxico à la Nietzsche podería ter para a análise dos discursos de poder que configuran aos individuos (Foucault, 1978, 181). E é que, para o filósofo francés, máis que unha categoría esencial, o suxeito é o resultado en constante modulación dun proceso de subxectivación. O suxeito é algo que se está a construír, a 
configurar, en virtude dunha serie de discursos/prácticas ${ }^{2}$ que reproducen formas de poder non monopolizadas por ninguén, pois este é asimilado, empregado e propagado por todos os individuos. Por esta razón: "El individuo, su subjetividad, su identidad, es el producto de una relación de poder que se ejerce sobre los cuerpos, las multiplicidades, los movimientos, los deseos, las fuerzas" (Sossa \& Brange, 2014, 110). Porén, que o exercicio de poder sexa algo que non se poida posuír con carácter de exclusividade non se segue que este non se presente nos distintos marcos sociais e culturais que conforman a historia mediante formas predominantes. Este feito condúcenos ao concepto de dispositivo. Por este, entenderá o noso autor unha rede composta por toda unha miscelánea de elementos que van dende os propios discursos ata as institucións arquitectónicas. ${ }^{3}$

Para Foucault as sociedades industriais propias da Modernidade son sociedades disciplinarias caracterizadas polo emprego de toda unha serie de tecnoloxías de disciplina sobre o corpo dos individuos a través da reclusión (no cárcere, no psiquiátrico, no hospital, na fábrica, na escola...). Un exemplo paradigmático disto mostrarao o francés na súa coñecida Historia da loucura, na cal desvélanos como o internamento masivo propio do século XVII se atopa fortemente relacionado cunha profunda crise económica e, en consecuencia, cunha nova forma de comprender a tolería (Foucault, 1979). Esta comprensión suporá finalmente a aparición dunha serie de dispositivos cunha dobre función que, como trataremos en apartados ulteriores, se reserva do mesmo xeito a escola. A saber: i) a preparación dos individuos para a vida laboral e ii) a formación de suxeitos dóciles e cómplices cos dispositivos de poder predominantes.

2 Cando Foucault fala de discursos se está a referir aos mecanismos de poder que configuran aos suxeitos, non a unha expresión verbal expresada por ningún suxeito (Poster, 1987, 123). Mentres que estas últimas poden ser consideradas formas de discurso, os discursos non se poden equiparar a formas verbais. Así, o filósofo rachará coas distincións coñecemento/poder ou discurso/práctica ao entender que estas dicotomías comparten un único referente. A saber, o feito de que toda acción reproduce unha forma de poder encuberta (Foucault, 2013, 14).

3 A definición máis clara ofrecida acerca do concepto de "dispositivo" está presente nunha entrevista realizada por Alain Grosrichard, onde o francés afirma: "Lo que trato de situar bajo ese nombre es, en primer lugar, un conjunto decididamente heterogéneo, que comprende discursos, instituciones, instalaciones arquitectónicas, decisiones reglamentarias, leyes, medidas administrativas, enunciados científicos, proposiciones filosóficas, morales, filantrópicas; en resumen: los elementos del dispositivo pertenecen tanto a lo dicho como a lo no dicho. El dispositivo es la red que puede establecerse entre estos elementos" (Grosrichard, 1978, 171). 
O control hexemónico da conduta dos individuos foi levado a cabo na Modernidade, durante o capitalismo industrial, a través da disciplina entendida como "estrategia de normalización" que "busca fiscalizar y controlar las conductas, comportamientos, aptitudes y preferencias, a través de diferentes formas" (Sossa \& Brange, 2014, 103) ou, dito cos termos do propio Foucault: "La disciplina 'fabrica' individuos; es la técnica específica de un poder que se da a los individuos a la vez como objetos y como instrumentos de su ejercicio" $(1998,175)$. Este tecido social controlado determínase a través do modelo do panóptico benthamiano presentado na obra Vixiar e Castigar (1998) do propio Foucault. É dicir, a disciplina sobre o corpo, o control sobre as súas prácticas (discursivas) se configura maioritariamente coa vixilancia permanente, xa non coa reclusión e completa marxinación precedente. Grazas a este modelo de control, o poder nas sociedades disciplinarias xa non se representa cun único rostro, pois agora calquera pode ocupar o lugar do controlador de tal modo que agora o exercicio do poder é máis económico e eficaz.

Coa aparición do capitalismo avanzado e, asemade, da Posmodernidade entendida como "reflexo" sociocultural ou "parte concomitante" deste 4 (Jameson, 2001, 12), fará acto de presenza un novo exercicio de poder. As sociedades disciplinarias foron substituídas por sociedades de control, algo do que, segundo afirma Deleuze, chegou a decatarse o propio Foucault (Deleuze, 2006, 273). Se os peches e a vixilancia perpetua foron os moldes a través dos cales configurar o comportamento dos individuos, agora esta configuración lévase a cabo dunha maneira, se cabe, moito máis económica. Nas actuais sociedades de control xa son se empregan os moldes, senón as modulacións (Deleuze, 2006, 279). A dependencia á observación allea rematou para dar pé a unha autovixilancia moito máis "cruel e enfermiza", “depresiva” (Han, 2012, 29). O exemplo proposto por Deleuze contrapón o traballo da fábrica co da empresa contemporánea: "La fábrica hacía de los individuos un cuerpo" $(2006,280)$, que operaba a través da mirada do patrono, mentres que "[1]a empresa, en cambio, instituye entre los individuos una rivalidad interminable a modo de sana competición” (Ibid.). O poder é exercido nas nosas sociedades do control, así pois, dende os propios suxeitos. Estes son os responsables do que lles suceda, do seu porvir.

${ }^{4}$ Polo tanto, seguindo a autores como Baudrillard (1988) ou Jameson (2001), neste traballo entenderemos por Posmodernidade a esfera sociocultural do neoliberalismo propio da nosa sociedade. 
Afirma Pablo Esteban Rodríguez no seu artigo “¿Qué son las sociedades de control?” (2008) que o proceso de normalización de determinadas prácticas se atopa nas nosas sociedades de control en catro vertentes. A primeira consiste no medo en virtude da lóxica da exclusión (Rodríguez, 2008, 8). Isto é, os individuos poden sobrevivir no marco do capitalismo posindustrial grazas ao consumo, que poden levar a cabo coa retribución salarial que obteñen coa produción. En consecuencia, para non ser marxinados do marco social é preciso que, dende a adolescencia, acepten o discurso hexemónico e actúen en consecuencia. Desta forma o medo, por exemplo ao desemprego, ou o previo estrés causado polo sentimento de necesidade de formar parte do mercado laboral, son hoxe unha constante cuxo sentido recae nese exercicio de poder que procura o mantemento do statu quo. A segunda vertente destacada consiste na novidade dos mass media (Ibid.). Dada a importancia deste aspecto para o noso traballo desenvolverémolo máis minuciosamente, xunto ao anterior, con posterioridade. "La modulación y la materialidad de la información” (Rodríguez, 2008, 9) é o terceiro elemento, segundo Esteban Rodríguez, configurador do suxeito da sociedade de control. "Información" provén etimoloxicamente de "informare", isto é, "dar forma" (Romano, 2007, 36). Así, a información que recibimos nos modula, precisa o modo en que nos debemos comportar pois, como di Vicente Romano con certa sorna, "si se quiere una persona que acepte coches defectuosos, pongamos por caso, no se le pueden proporcionar informaciones que provengan de un ingeniero agrónomo" (2007, 37). A consecuente masificación da información propicia que o presente poda ser analizado como un triunfo do "dataísmo", ideoloxía que viría a defender que todo se debe transformar en datos e información (Han, 2014, 88). O almacenamento dixital de toda a información relativa as nosas vidas, o "Big Data", é un fenómeno que ten na nosa "sociedade da transparencia" aos propios individuos como cómplices. A razón reside no proceso polo que a identidade do individuo se configura en relación coa identidade que os outros lle atribúen: "No puede construirse una identidad propia prescindiendo de la identidad para-los-otros" (Roca, 2005, 336). O suxeito precisa, para conformar unha identidade, concibir, coma nun xogo de espellos, aquilo que supón que pensan os demais sobre el mesmo. Na liña do que acabamos de expoñer, a cuarta vertente a través da cal opera a sociedade de control, consiste na progresiva desaparición da fronteira entre o público e o privado (Rodríguez, 2008, 9). O feito remarcado de que "la definición de lo normal se produce fuera del espacio y el tiempo disciplinarios" (Rodríguez, 2008 , 10) supón, en definitiva, que paseniño a fronteira entre o público e 
o privado se dilúa. As novas tecnoloxías mostran exemplarmente como o "normal" é atoparse en conexión constante co outro (Justo Herrero, 2016, 228-9).

Estes catro elementos dan conta do paso das sociedades disciplinarias cara sociedades de control. Estas últimas, unhas sociedades que inscritas do marco do capitalismo tardío recoñece aos individuos exclusivamente conforme ao binomio produtor/consumidor. Deste modo, o comportamento normalizado ${ }^{5}$ non provirá da vixilancia nin da disciplina externas, senón daquela que exerce o individuo consigo mesmo.

\subsection{O papel dos mass media}

No anterior apartado vimos de que maneira a sociedade de control dos nosos días, propia polo tanto da Posmodernidade, determina a conduta, ou incluso a identidade, dos individuos en contraposición cos modos propios das "sociedades disciplinarias". Se ben este traballo se centrará no espazo escolar en particular e no sistema educativo en xeral como construcións interesadas dunhas subxectividades concretas, cremos que resulta sumamente importante facer certa fincapé no papel que cumprirán nesta construción os mass media. Esta importancia se manifestará igualmente no propio espazo escolar ao dar como resultado o reforzamento do autorecoñecemento dos individuos como produtores/consumidores e, simultaneamente, unha contradición entre a rapidez e banalidade exportada polos mass media coa calma e profundidade que debería fomentar a escola.

No capitalismo posindustrial, incluso en maior medida que a produción, o consumo ocupa un papel extremadamente esencial (Bauman, 2003, 82). En consecuencia, o fomento do consumo será unha das grandes empresas que se adopte dende os mass media, por exemplo a través da publicidade. A reificación ou constitución en mercancía de todo cando poidamos imaxinar, a identificación da felicidade co consumo, a hiperestimulación sensorial, a comprensión da construción da identidade en función da alteridade, o medo ao aburrimento, a creación de necesidades ou a necesidade de satisfacción inmediata son algunhas das ideas que nos bombardean con só acender o televisor. Vexámolas sucintamente.

\footnotetext{
${ }^{5}$ No que respecta a este concepto resulta interesante traer a colación unha aclaración de Foucault, presuposta na nosa exposición, que reza: "Cuando un juicio no puede enunciarse en términos de bien y de mal se lo expresa en términos de normal y de anormal" (Foucault, 1978, 41). Consecuentemente, o comportamento catalogado como "normal" aglutina un xuízo de valor positivo que o presentará eo ipso como modelo a imitar.
} 
Na súa Teoría da posmodernidade Jameson caracteriza a nosa como unha situación de "esquizofrenia no sentido lacaniano" (2001, 47-8). Os suxeitos posmodernos serían incapaces de dixerir holisticamente, coma un todo orgánico, a cadea de significantes que viría a constituír o sentido da súa vida. Así, o esquizofrénico destacaría como tal por ser incapaz de unificar o tempo coa súa "vida psíquica", producíndose por isto unha ruptura na devandita cadea, polo cal o suxeito ficaría recluído nunha experiencia de significantes illados, de "presentes puros" (Jameson, 2001, 48). Esta idea resulta sumamente interesante ao remitirnos a unha concepción do presente totalizador represor dos proxectos a longo prazo (Roca, 2005, 333-4). O resultado será o predominio, nesta Posmodernidade, dunha noción do tempo que destaca a rapidez, a instantaneidade, a necesidade de satisfacción inmediata e, por ende, o curto prazo como ideal último: "La eficiencia del tiempo como medio para conseguir valor tiende a aproximarse al infinito" (Bauman, 2003, 127). Que se pretende conseguir con este nova conciencia do tempo? É presumible que o fomento do consumo. A consolidación dun "homo economicus" preocupado primordialmente pola obtención de beneficios co fin de satisfacer, o máis inmediatamente posible, os seus desexos.

Os mass media exercen un dominio dos individuos, recordemos que ao situarnos en sociedades de control a través da construción de subxectividades, coa produción desexante (Baceiredo, 2013, 26). Ao estar exposto a un bombardeo de marketing, o cal se serve sempre dunha linguaxe imperativa (Baceiredo, 2006, 57), o individuo experimenta como agroman na súa psique toda unha serie de apetencias asimiladas como carencias. En tanto suxeitos desexantes, estes senten a necesidade dunha "satisfacción vana constante", necesitan sempre dun algo máis, o "plus-de-gozar" de Lacan canalizado no consumo (Lacan, 2008, 11-24; Ema, 2009, 230). Servíndose destes medios de comunicación, o capitalismo enfoca esta produción desexante cara o mercado cunha perpetua "promesa de peche" sempre por vir (Ema, 2009, 244).

Outra das principais características polas que se rexen os mass media para a construción das subxectividades é, ademais da creación de desexos ou da prioridade do curto prazo, o torpor sensorial. Co gallo de abranguer o máximo nivel de atención, as multinacionais anuncian os seus produtos dos modos máis diversos. Mais, a pesar desta disparidade, semella claro que a tendendencia non segue outro camiño que o da hiperestimulación sensorial (Han, 2012, 46). Como se destaca en numerosos traballos (véxanse, por exemplo: Almarcha \& Campelo, 1999, 69-82; Alzandúa, 2012, 177-208; Radl Philipp, 2012, 21-34; Justo Herrero, 2016, 45-98), ao ser a adolescen- 
cia aquela etapa vital sobre a que as empresas multinacionais poñen o foco para a captación de suxeitos de consumo, as cores e sons escintilantes están principalmente orientados a ela. En calquera dos casos, o resultado máis visible deste proceso de hiperestimulación e da nova conciencia do tempo destacada, consiste na incapacidade dos suxeitos modulados desta guisa para abstraer, para non procesar a información, obrigándoos "a permanecer na anécdota" (Baceiredo, 2006, 50). Os individuos experimentan hoxe unha "fatiga cognitiva" froito da "sobrecarga estimular" que supón "o esgotamento da capacidade atencional" (Baceiredo, 2006, 67). O cal, como suxire Baceiredo, producirá suxeitos indiferentes aos seus actos, amorais, engulidos por unha lóxica consumista que está a "enquistar as capacidades mentais" para dar lugar a un "suxeito vulnerable á manipulación” (2006, 125).

Neste punto atopa un posto privilexiado no noso imaxinario social o antedito medo ao aburrimento. Os suxeitos posmodernos, habituados á sobreexcitación sensorial precisan de emocións externas constantemente. As dificultades causadas por este feito abarcan a lectura pausada dun libro sen a presenza dun móbil ou a mesma capacidade para pensar. Estas son ilustradas por Ana Justo no plano da escola:

Mi experiencia como profesora me permite además observar ciertas diferencias entre los adolescentes actuales y los adolescentes de mi generación en el modo de comportarse en el aula. Hoy tienen menos reparos en manifestar inquietud y aburrimiento si la clase no presenta cambios de actividad cada cierto tiempo y si es demasiado teórica $(2016,300)$.

Un último aspecto que consideramos importante resaltar neste apartado, xa que é apuntalado con moita forza polos mesmos mass media, é a conformación da propia identidade a través da alteridade: "la creación de la identidad requiere de la experiencia y relación con el otro, con aquel distinto a mí pero del que dependo para entenderme y reconocerme como sujeto" (Justo Herrero, 2016, 137). Os novos medios de comunicación e información, fundamentalmente as redes sociais, ofrecen hoxe a oportunidade aos individuos de formar parte do espazo público. Dada a limitación que contrae esta adquisición da identidade a través dos mass media e redes sociais en relación co clásico tête-à-tête, estamos a vivir nunha época onde o valor social recae no superficial ou na mera fachada (cuxo neoloxismo contemporáneo sería o "postureo”):

El valor personal se mide por el poder, la riqueza, la posibilidad de consumo y la atención que los individuos son capaces de despertar diariamente en el espectáculo cotidiano, tal como la calidad artística de los programas y eventos culturales es in- 
dicada, casi exclusivamente, por los índices de venta y audiencia [...] la imagen que se le ofrece al prójimo, ya sea falsa o verdadera, es el punto relevante en el proceso social (Pacheco Filho, 2012, 120).

A importancia da imaxe para a aceptación social, especialmente durante a adolescencia, repercutirá negativamente para todos aqueles individuos cuxo corpo non se adapte ao canon, por exemplo, de beleza, propios do discurso imperante (Almarcha \& Campelo, 1999) presentes ata saciedade nos mass media. Alén desta dimensión concreta da problemática, cabe destacar o punto máis sobresaliente da mesma. Este recae sobre a substitución do ser polo ter: os individuos serán na medida en que se expoñan ante o resto, e serán para ben canto máis poidan mostrar que teñen nesta exposición. Antes que ninguén máis, en definitiva, aqueles que dispoñan de máis recursos terán un dilatado espectro de posibilidades mercantís que lles permitirá satisfacer o "desexo de consumo" (Bauman, 2003, 80) que, en consecuencia, os farán os modelos ideais de felicidade a seguir. Co espírito do "impossible is nothing", e como o burro que se move inutilmente tras a cenoria que ten diante de si, o resto dos individuos anhelan posuír esa imaxe monopolizada polos que poden satisfacer con maior asiduidade o desexo consumista.

Feita unha breve descrición do modo en que as sociedades de control configuran aos suxeitos posmodernos a través dos mass media co obxectivo de normalizar o seu papel de produtor/consumidor, a pregunta que poderíamos formular é: Como se pode superar dende a escola esta configuración do suxeito, particularmente do adolescente posmoderno? Quérese dicir, como pode a escola, por exemplo, educar aos estudantes en valores cando fóra dela o socialmente valioso, por ser o maioritariamente consumido, o ofertado pola televisión e compañía, é a violencia extrema (Romano, 2007, 106)? Como podería a escola ensinar a ler e a escribir con corrección cando certos programas televisivos ou os novos medios de interacción social, na ansia de instantaneidade, fomentan en certo grao o analfabetismo? Aparentemente, puideramos dicir, o problema consiste en que entre o sistema educativo e o sistema capitalista posindustrial media unha contradición case in terminis. Mais, como veremos, o verdadeiro problema de hoxe non reside nesa contradición, senón no proceso polo cal a escola deveu nun espazo cómplice co sistema (Fernández Enguita, 1990, 117-272). 


\section{A escola e a educación posmoderna}

\subsection{A escola como resposta ás necesidades da industrialización}

Tal e como a entendemos na actualidade, a escola é unha institución que xorde froito do século XIX cunha razón de ser enraizada na Modernidade. Esta razón de ser é concretamente dobre: por unha parte atopamos un novo senso asociado á infancia propio desta época (Alzandúa, 2012, 177-208) e, pola outra, unha conxuntura socio-económica propiciada pola crecente industrialización que suporá a necesidade de ensinar certas destrezas aos rapaces en tanto traballadores potenciais (Fernández Enguita, 1990, 178212; Pardo \& García Tobío, 2003, 39-85; Pardo, 2016, 25-42).

Como mantén Philippe Ariès na súa obra $O$ neno e a vida familiar no antigo réxime (1987), a concepción dos infantes variou en gran medida ao longo dos anos. Non será ata a Modernidade cando o infante cobre a visibilidade que se manterá ata os nosos días, soamente ensombrecida pola importancia primordial adquirida polo adolescente dende a segunda metade do século pasado. A infancia adquire na era moderna unha carga de novas significacións que propician a comprensión da mesma non tanto coma unha especie de "pequena adultez", senón como "adultos en potencia". Do mesmo xeito, esta concepción moderna da infancia espertará, asemade se reestrutura un novo modelo de familia, un sentimento de preocupación e coidado antes menos patente por parte dos pais. Estes comezan progresivamente a prestar maior atención ao coidado dos infantes dando como resultado "una reorganización en las relaciones afectivas al interior de la familia" (Mora, 2014, punto 3.1.). Nenos e nenas comezan a ser ollados coma suxeitos que requiren dunha atención especial, e non tanto como mera man de obra. Mais non debemos caer no erro de considerar que este recoñecemento social da infancia ven da man dunha preocupación polo seu benestar, ou, canto menos, non o debemos considerar como factor primordial. Como xa tivemos oportunidade de ver con anterioridade, a relevancia moderna da infancia, como o resto de procesos sociais, é o resultado dunha complexa rede de relacións de poder amalgamadas a unha determinada conxuntura socio-económica.

$\mathrm{O}$ auxe da produción científico-tecnolóxica orientada pola revolución científica xerará durante os séculos XVIII e XIX unha serie de inventos que modificarán completamente o modo de produción vixente ata entón. ${ }^{6} \mathrm{~A}$ revolución industrial resultante, co conseguinte triunfo da burguesía nesta

${ }^{6}$ En termos foucaultianos poderiamos dicir que achamos nestes séculos, poida que xa dende a invención da imprenta no século XV, unha nova episteme. Isto é, aquel conxunto 
época ilustrada (Mora, 2014, punto 2.4.), modulan a mentalidade moderna para dar lugar non só á antedita concepción da infancia, senón a toda unha produción fabril. Ante a comprensión de que a conservación do statu $q u o$ precisa sempre dunha mentalidade social cómplice, a reformulación da escola será o instrumento propicio para configurar a aqueles suxeitos -os infantes- que deberán aceptala (Mora, 2014, punto 2.4.).

Con todo, non podemos perder de vista que a escola universal foi un logro social de dilatada envergadura que recolleu, coa súa aparición, os intereses de moitos ilustrados progresistas que defenderon a necesidade de formar cidadáns libres e iguais, capacitados para facer valer os seus dereitos e o progreso social (Pardo \& García Tobío, 2003, 40). En oposición isto a un colectivo conservador convencido de que esa concepción da escola, lonxe de conformar a nova mentalidade requirida polo sistema, "contribuiría peligrosamente a transmutar el orden social establecido" (Pardo \& García Tobío, 2003, 40). Como deixou constancia o político liberal Bravo Murillo: "No necesitamos hombres que piensen, sino bueyes que trabajen" (Fernández Enguita, 1990, 124). Será deste conflito ideolóxico entre ilustrados por unha banda, e conservadores do novo sistema pola outra, do que agrome a escola harmonizando ambos intereses. Mais tan só en principio posto que se ben, como reclamaron os ilustrados, a escola se constitúe como institución universal dirixida a toda a poboación xuvenil, esta universalización resultou ser unha arma de dobre fío que en absoluto cumpriu as demandas do sector progresista (Pardo \& García Tobío, 2003, 42).

O motivo polo que esta conquista progresista tornou nunha vitoria conservadora reside na forma e contidos nos que se estrutura a escola. Dados "los peligros potenciales de un exceso de formación escolar" (Pardo \& García Tobío, 2003, 42), e aínda que os progresistas conseguiran o seu obxectivo de levar a educación aos fillos das clases traballadoras, os conservadores lograron pola súa parte que esta escola universal quedara dividida en dúas categorías, a "escola primaria" e a "escola secundaria", ás cales asistirían de maneira diferenciada os fillos das clases traballadoras e os das elites respectivamente (Ibid.). Esta distinción respondeu claramente a unha diverxencia de intereses acerca do lugar que infantes e mozos tiñan disposto cumprir no seu futuro. Os estudantes da escola secundaria estudarán aquelas materias

de condicións de posibilidade dos coñecementos que agroman nun momento histórico concreto. Desta noción de episteme dirá o francés que nos remite ao "fondo de qué a priori histórico y en qué elemento de positividad han podido aparecer las ideas, constituirse las ciencias, reflexionarse las experiencias en las filosofías, formarse las racionalidades para anularse y desvanecerse quizás pronto" (Foucault, 1968, 7). 
que lles permita manter o seu estatus privilexiado: "Las clases dominantes aprovecharán los privilegios que otorga el poder económico y formarán a sus hijos en las nuevas artes liberales, la economía, el comercio, las finanzas, las ciencias naturales, la física..." (Mora, 2014, punto 2.4.). Aos estudantes da escola primaria ou elemental se lles aporta unha formación intelectual mínima, baseada fundamentalmente en ler e escribir, e, especialmente, unha actitude que deben manter ao longo da súa futura vida laboral.

A escola primaria configura unhas subxectividades dóciles que acepten como o "normal" toda unha serie de costumes e valores que deberán reproducir nas fábricas. Hai que educar, en primeiro lugar, para que "aprendieran a respetar el orden social, pero no tanto que pudieran cuestionarlo" (Fernández Enguita, 1990, 125). Deste adoutrinamento constante se pasará á disciplina consistente en prácticas tan aparentemente inocentes, pero efectivas, como a puntualidade, o cumprimento dun horario e dunhas tarefas impostas, a orde ou a aceptación de toda unha serie de autoridades en orde de xerarquía (Fernández Enguita, 1990, 181). O estudante da escola primaria asume o seu rol social baixo a ilusión de que poderá, asumindo unha cultura do esforzo e da competencia, subir na escala social, lexitimando así, en definitiva, a visión meritocrática propia do sistema capitalista.

\subsection{A escola comprensiva no marco do Estado de Benestar}

No primeiro terzo do século XX terá lugar progresivamente unha reformulación da concepción da escola tal e como se desenvolvera no último século. A diferenciación curricular entre aqueles estudantes provenientes de familias traballadoras, destinados á escola elemental, e aqueloutros das familias acomodadas, propios da escola secundaria, comeza a poñerse en cuestión. A pesar de que o novo modelo educativo con finalidades asociadas á integración xa se comeza a levar a cabo nos EEUU a mediados do XIX (Pardo \& García Tobío, 2003, 68), en Europa haberá que esperar ata o século XX. O cambio sucede inicialmente en países nórdicos, como Noruega ou Suecia, que porán en marcha unhas reformas educativas destinadas a erradicar dita diferenciación a través da unificación curricular (García Pedraza, 2015, 135-152). Porén, as reivindicacións por parte dos progresistas dunha escola onde se busque unha verdadeira igualdade de oportunidades tan só cristalizarán con forza tras a Segunda Guerra Mundial (Pardo \& García Tobío, 2003, 44).

Os desastres producidos na primeira metade do XX serven de acicate para que numerosos estados acorden o compromiso de garantir un certo nivel de benestar básico (sistema sanitario, educativo, de pensións...) a toda 
a cidadanía co fin de favorecer un novo sistema de produción-consumo máis "humano". Trátase así de facer compatible o modelo socio-económico capitalista coa democracia asegurando un espazo de intervención estatal para mitigar os diversos problemas que o primeiro viña amoreando (Pardo, 2016, 29). Deste modo aparece nos anos 50 o denominado "Estado do Benestar" que, no plano educativo, impulsará a integración social e o reparto equitativo do coñecemento.

Unha vez máis será un país nórdico, Suecia, quen lidere o proceso para a formación desta "escola comprensiva" que pretende non só a unificación curricular, senón a igualdade de oportunidades ao establecer un determinado período de educación obrigatoria. Así, cunha bagaxe previa que se remonta ata os anos 30, Suecia comezará a experimentar en 1950 o modelo da "escola comprensiva", edificándose finalmente en lei educativa en 1962 (García Pedraza, 2015, 137). Na meirande parte dos países representantes do "Estado do Benestar" a promulgación das novas leis educativas será unha constante que se espallará ao longo dos anos 50 e, especialmente, 60.

Non podemos desestimar, pois, o feito de que a "escola comprensiva" supuxo que certos ideais demandados no seu momento polos ilustrados progresistas fronte aos conservadores se puideran facer realidade. Agora ben, lonxe de perpetuarse no tempo, a "escola comprensiva” gozará dunha esperanza de vida máis ben reducida ante a crecente hexemonía da ideoloxía neoliberal.

\subsection{Crise escolar e reformas educativas neoliberais}

O "Estado do Benestar" sofre a partires dos anos setenta un duro revés asestado pola posta en práctica da ideoloxía neoliberal (Pardo \& García Tobío, 2003, 47). Ante as medidas levadas a cabo en nome deste "Estado do Benestar", economistas da Escola de Austria, como Friedrich Hayek (véxase, por exemplo: Hayek, 1995, 121-135), sosterán, pola contra, que toda forma de planificación económica non dirixida cara o fomento da competencia individual, garante segundo o neoliberalismo do éxito colectivo (Pachecho Filho, 2012, 120), comportaría unha forma de totalitarismo incompatible co respecto ás liberdades dos individuos. En aras de manter esta máxima, o Estado non pode quebrar a igualdade formal da cidadanía en beneficio de determinados colectivos con menor capacidade económica (Pardo \& García Tobío, 2003, 48). Esta será unha máxima que será asumida polas novas formas de goberno e economías neoliberais iniciadas en Gran Bretaña e os Estados Unidos (EE. UU.): "Desde que Thatcher en el Reino Unido y Reagan en los EE.UU iniciaran esta senda en 1979 y 1981 
respectivamente, casi todos los gobiernos del mundo, con independencia de su signo político, desarrollaron políticas neoliberales" (Pardo \& García Tobío, 2003, 51).

As consecuencias que este novo panorama político e económico tiveron nas sucesivas reformas educativas manifestáronse especialmente na implantación da chamada "Nova Xestión Pública", entendéndose por tal o "programa de reforma del sector público que aplica conocimientos e instrumentos de la gestión empresarial y de disciplinas afines" (Verger \& Normand, 2015, 599). Trátase con este conxunto de medidas implantadas a nivel global de introducir a mentalidade posindustrialista en servizos públicos, como a educación; con especial fincapé neste último caso, moi posiblemente, por tratarse dun dos sectores da administración pública cunha "mayor dotación presupuestaria y de personal" (Verger \& Normand, 2015, 600). Así, este programa virá cobrando cada vez un maior peso na organización e xestión das escolas deixando paso a unha comprensión empresarial da escola (Bernal \& Vázquez Toledo, 2013, 39), tal e como ilustra a seguinte táboa, froito dunha adaptación de Gunter \& Fitzgerald (2013, 213-219) por Verger \& Normand $(2015,602)$ :

\section{Táboa 1}

\begin{tabular}{|l|l|}
\hline PRINCIPIO NGP7 & POLÍTICAS EDUCATIVAS \\
\hline $\begin{array}{l}\text { Gestión profesional de los servicios } \\
\text { públicos }\end{array}$ & $\begin{array}{l}\text {-Profesionalización y empoderamiento de los } \\
\text { directores de escuela }\end{array}$ \\
\hline $\begin{array}{l}\text { Normas y medidas de desempeño } \\
\text { más explícitas }\end{array}$ & $\begin{array}{l}\text {-Definición de indicadores de calidad y de } \\
\text { benchmarks sobre "éxito" educativo } \\
\text {-Estándares curriculares comunes }\end{array}$ \\
\hline Énfasis en el control de resultados & $\begin{array}{l}\text {-Evaluación externa de los resultados y del } \\
\text { rendimiento escolar }\end{array}$ \\
\hline $\begin{array}{l}\text { Desagregar el sector público en } \\
\text { unidades de gestión más pequeñas }\end{array}$ & -Autonomía escolar, school-based management \\
\hline $\begin{array}{l}\text { Mayor competición en el sector } \\
\text { público }\end{array}$ & $\begin{array}{l}\text {-Subsidios públicos a las escuelas privadas } \\
\text {-Financiación per cápita } \\
\text {-Publicación de los resultados obtenidos por las } \\
\text { escuelas en pruebas estandarizadas }\end{array}$ \\
\hline $\begin{array}{l}\text { Emular el estilo gerencial del sector } \\
\text { privado }\end{array}$ & $\begin{array}{l}\text {-Flexibilidad de la escuela en la contratación y } \\
\text { el despido } \\
\text {-Estilos gerenciales de dirección de la escuela }\end{array}$ \\
\hline $\begin{array}{l}\text { Mayor disciplina/parsimonia en el } \\
\text { uso de recursos }\end{array}$ & $\begin{array}{l}\text {-Financiación de las escuelas en base a resultados } \\
\text {-Remuneración docente basada en criterios de } \\
\text { mérito/productividad }\end{array}$ \\
\hline
\end{tabular}

${ }^{7}$ As siglas "NGP” correspóndense coa denominación en castelán da "Nova Xestión Pública”. 


\subsection{O proceso de subxectivación do adolescente posmoderno dende a escola}

En apartados anteriores apuntáronse os motivos polos cales a infancia adquire unha nova significación na Modernidade, fundamentalmente debido a unha nova conxuntura socio-económica, o auxe do modelo de produción fabril, que entre outras cousas suporá: i) un éxodo rural sen precedente (Fernández Enguita, 1990, 30-34) e ii) a instauración dun sistema educativo que pretende ser universal, exercido dende un topos concreto, a escola, co fin de constituír unhas subxectividades funcionais para o novo modelo de produción e capacitadas para introducirse nel. Tras a Segunda Guerra Mundial este proceso de subxectivación deixará de estar focalizado na infancia para dirixirse a unha nova categoría de individuos progresivamente máis destacada, a adolescencia.

Caracterizada por ser unha etapa onde a necesidade de "satisfacción inmediata" (Bauman, 2003, 127) está presente dun xeito paradigmático, entre outros aspectos non menos relevantes, como a maior susceptibilidade de cara a influencia allea (Justo Herrero, 2016, 211), o adolescente convértese no suxeito perfecto de cara ao fomento do ideal consumista. Deste xeito, non só será a adolescencia o novo "blanco de mercancías" (Anzaldúa, 2012, 194), senón que ao dirixirse o marketing con especial intensidade a este sector da poboación, todo o imaxinario social da Posmodernidade quedará vernizado co ideal da eterna xuventude ou o "síndrome de Peter Pan" (Justo Herrero, 2016, 330). Vivimos en sociedades nas que se promove e valora o ser "eternos adolescentes" (Baceiredo, 2006, 73), en "sociedades adolescentizadas" onde, entre o océano relativista que nos circunda, o discurso normalizado se atopa na busca xeral da beleza superficial, da satisfacción inmediata, na ansia de consumo, etc. (Justo Herrero, 2016, 359). Recuperando a problemática coa que concluímos o apartado 2, a pregunta que cabe facerse, en definitiva, seguindo a Ana Justo é, referida á pretensión dunha verdadeira educación, “¿cómo conseguirlo en una sociedad que además hace mucho dinero convirtiendo al adolescente en un esclavo consumidor?" $(2016,282)$.

A pesar de que cada vez conta cun menor papel nos procesos de subxectivación dos individuos (Mora, 2014, punto 2.4.), a escola realiza un proceso de selección no que se determinará que rol cumprirán os estudantes na sociedade de cara a súa inserción no mercado laboral. Este proceso de selección servirá para manter a ilusión de que a distribución dos roles sociais son resultado da competición, en igualdade de condicións, na que es- 
tán inmersos todos os individuos en idade de escolarización. No que resta de traballo intentaremos mostrar de que maneira este espírito mercantil se introduce nas actuais formas de organización escolar. Co fin de analizar esta constitución do suxeito posmoderno no espazo educativo, agora dende unha dimensión político-institucional, tomaremos como referencia o actual caso español da LOMCE.

\subsubsection{O curriculo escolar dende a racionalidade técnico-instrumental: o caso da LOMCE}

Se ben a LOMCE asumirá con suma fidelidade os principios do neoliberalismo en toda a súa amplitude, neste derradeiro apartado faremos fincapé naquel aspecto da lei que conta cunha maior afinidade co destacado fin educativo da escola primaria da Modernidade. Isto é, a concepción da escola como institución que cumpre a dobre función de aportar aos estudantes os coñecementos demandados polo mercado laboral e, pola outra banda, a de seleccionar aqueles estudantes aos que se lle aportará a cualificación necesaria para o desenvolvemento de determinados roles laborais.

\section{i. Finalidades: as competencias}

Como sinala Juan Carlos Pardo, a incorporación das competencias á escola respondeu inicialmente ao informe "Education and European Competence", elaborado en 1989 polo grupo empresarial European Round Table of Industrialists $(2016,38)$. Este informe, que pretende adaptar o currículo escolar ás necesidades empresariais a través da instauración dunha serie de competencias que deberían ser desenvoltas, influirá en non escasa medida en conxunción con outras demandas procedentes do mundo empresarial no Consello Europeo de Lisboa celebrado no ano 2000. Así, a razón de ser das competencias educativas responde precisamente á conciliación entre as necesidades do mercado laboral e a educación requirida aos estudantes. Isto último na medida en que entendamos as competencias, no caso da LOMCE "competencias clave", como unha serie de habilidades, saberes ou destrezas que os estudantes deben poder levar a práctica.

A través do noso actual caso, da LOMCE, e das sete competencias clave presentes no currículo ${ }^{8}$ o que se pretendería é continuar cunha "lóxica das

\footnotetext{
${ }^{8}$ Estas son: "comunicación lingüística”, “competencia matemática y competencias básicas en ciencia y tecnología", "competencia digital", "aprender a aprender", "competencias sociales y cívicas", "sentido de la iniciativa y espíritu emprendedor", "conciencia y expresiones culturales" (Orden ECD/65/2015, de 21 de enero, por la que se describen las relaciones entre las competencias, los contenidos y los criterios de evaluación de la educación primaria, la educación secundaria obligatoria y el bachillerato, 29 de enero de 2015).
} 
competencias" (Pardo, 2016, 25-42) co fin de modular unhas subxectividades acorde ao sistema. Dun modo paradigmático atopamos na actual lei educativa a competencia do "Sentido de iniciativa e espírito emprendedor" acorde a cal a formación dos estudantes:

debe incluir conocimientos y destrezas relacionados con las oportunidades de carrera y el mundo del trabajo, la educación económica y financiera o el conocimiento de la organización y los procesos empresariales, así como el desarrollo de actitudes que conlleven un cambio de mentalidad que favorezca la iniciativa emprendedora... (Orden ECD/65/2015, de 21 de enero, por la que se describen las relaciones entre las competencias, los contenidos y los criterios de evaluación de la educación primaria, la educación secundaria obligatoria y el bachillerato, 29 de enero de 2015).

Atopamos nesta competencia unha proba de valía de como o fin da escola está amalgamado á preparación para a inserción laboral. A implantación desta clase de "lóxica das competencias" envolverá unha serie de funcións de normalización entre as que Pardo $(2016,39-40)$ destaca: i) a reificación das persoas en mercadoría, derivado do cal estas "no tienen más alternativa que luchar unas contra otras por un trabajo escaso" (Pardo, 2016, 39); ii) a creación dun sentimento de lexitimidade cara o statu quo ao volver aos individuos más dóciles e útiles para o mercado (Ibid.); iii) a busca da "individualización de las relaciones laborales" (Pardo, 2016, 40) ao rachar esta competencia cos vínculos colectivos da cidadanía e iv) a asunción da desigualdade socio-económica como "consecuencia del orden natural del mercado" (Ibid.).

\section{ii. Contidos: a desvalorización dos saberes humanísticos}

A constante desvalorización dos saberes humanísticos nas sucesivas leis ou reformas educativas é unha constante que non nos pode resultar indiferente. É posible que un dos casos máis representativos sexa o da filosofía, disciplina que se ben ven sendo "maltratada" en sucesivas leis educativas (Altares \& Álvarez, 2015), en ningún outro momento foi tan castigada como na LOMCE. A principal razón disto semella responder á "inutilidade" da filosofía para a satisfacción do principal rol que viría a cumprir nos nosos días o sistema educativo: a formación de individuos produtores e consumidores conforme ás demandas do mercado.

Alén da escandalosa redución das horas reservadas para esta disciplina na escola, resulta significativa a introdución no currículo da súa única materia de carácter obrigatorio a nivel estatal, a "Filosofía" de $1^{\circ}$ de Bacharelato, de contidos como "La filosofía y la empresa como proyecto racional" ou "El modo metafísico de preguntar para diseñar un proyecto, vital y de empresa" (Real Decreto 1105/2014, de 26 de diciembre, por el que se 
establece el currículo básico de la Educación Secundaria Obligatoria y del Bachillerato, 3 de enero de 2015).

Podemos ver con estes contidos ata que punto a competencia do "Sentido de iniciativa e espírito emprendedor" desprega os seus tentáculos na LOM$\mathrm{CE}$, chegando a invadir as terras dos saberes humanísticos. Non obstante, non parece especialmente comprometedor afirmar que a través do ensino da filosofía, entre outras disciplinas menosprezadas no sistema educativo, se poden desenvolver a meirande parte dos catorce obxectivos propostos no artigo 25 do Real Decreto 1105/2014. Por este motivo, consideramos moi atinada a reflexión de Pardo cando apunta:

De ahí que, con la trampa, con la farsa de la empleabilidad, las administraciones educativas elaboren currículos sensibles a las «necesidades» empresariales. El caso de la LOMCE es paradigmático, porque pone el acento en las lenguas, en las matemáticas, en las ciencias y en la tecnología, y hace de la cultura empresarial y el «espíritu emprendedor» un contenido transversal de todas las materias $(2016,39)$.

Este caso paradigmático sérvenos de apoio para aseverar o carácter fortemente interesado da LOMCE para a conformación de determinadas subxectividades. En particular, as que caracterizamos como subxectividades da Posmodernidade. Motivo este que nos permite explicar o por que da redución e eliminación de materias profundamente vinculadas á formación intelectual e moral dos individuos, asemade se fomenta outro tipo de ensino máis relacionado cos intereses do mercado. Entre os que se atopan materias como as "Ciencias aplicadas a la actividad profesional", "Iniciación a la actividad emprendedora y empresarial”, "Economía”, "Economía de la empresa" ou "Fundamentos de administración y gestión" (Decreto $86 / 2015$, de 25 de junio, por el que se establece el currículo de la educación secundaria obligatoria y del bachillerato en la Comunidad Autónoma de Galicia, 29 de junio de 2015).

\section{iii. Avaliación: a prevalencia da estandarización}

Aqueles aspectos que se consideran dunha maior relevancia para a avaliación das materias formarán parte dos chamados "estándares de aprendizaxe" na LOMCE. Estes son definidos como as:

especificaciones de los criterios de evaluación que permiten definir los resultados de aprendizaje, y que concretan lo que el estudiante debe saber, comprender y saber hacer en cada asignatura; deben ser observables, medibles y evaluables y permitir graduar el rendimiento o logro alcanzado (Real Decreto 1105/2014, de 26 de diciembre, por el que se establece el currículo básico de la Educación Secundaria Obligatoria y del Bachillerato, 3 de enero de 2015). 
Por exemplo, con respecto ao currículo de "Filosofia" de $1^{\circ}$ de bacharelato, ante o criterio de avaliación consistente en: "3. Conocer y comparar las explicaciones dadas desde las grandes cosmovisiones sobre el universo" atopamos entre os seus estándares de aprendizaxe: "3.1. Explica y compara dos de las grandes cosmovisiones del Universo: el paradigma organicista aristotélico y el modelo mecanicista newtoniano" ou "3.2. Describe los caracteres esenciales de la interpretación de la realidad relativista, y cuántica contemporánea, explicando las implicaciones filosóficas asociadas a ellos" (Real Decreto 1105/2014). Isto implica que tan só para o criterio de avaliación mencionado, os alumnos de $1^{\circ}$ de Bacharelato "deberán saber" explicar, describir e empregar unha cantidade de coñecementos sumamente extensos e complexos. O cal fai a todas luces absurda, por inviable, a función desta estandarización.

Non obstante, é posible que o aspecto máis destacable desta nova estandarización non sexa a imposibilidade da súa praxe, senón, en primeiro lugar, a súa propia presenza. Xa nos inicios do preámbulo da LOMCE podemos ler a asunción clave para esta estandarización, isto é, a diferenciación naturalizada entre os distintos estudantes. Estes teñen distintos "talentos" que os remitirán, a priori a través da súa potenciación, a diferentes "traxectorias":

Todos los estudiantes poseen talento, pero la naturaleza de este talento difiere entre ellos. En consecuencia, el sistema educativo debe contar con los mecanismos necesarios para reconocerlo y potenciarlo. El reconocimiento de esta diversidad entre alumno o alumna en sus habilidades y expectativas es el primer paso hacia el desarrollo de una estructura educativa que contemple diferentes trayectorias (Ley Orgánica 8/2013, de 9 de diciembre, para la mejora de la calidad educativa, 10 de diciembre de 2013).

$\mathrm{O}$ que se pretende é facer recaer os diferentes resultados provenientes das avaliacións sobre unha distinción natural de "talentos". Por suposto, non se trata aquí de cuestionar a diversidade presente nas aulas, senón a xustificación a partir desta das diferentes "traxectorias" dos estudantes, fundamentalmente entre a Formación Básica para aqueles que non acaden os requisitos establecidos polos estándares, e a orientación universitaria. Con todo, cómpre lembrar que os distintos resultados acadados no proceso de avaliación semella responder máis a unha serie de circunstancias socioeconómicas (Pérez Gómez, 1993, 16-27; Ruiz de Miguel, 2001, 81-113), como os recursos ou a formación intelectual das familias, ou culturais (San Fabián, 1999, 25-30), que a unha especie de disimilitude natural. Agora ben, polas mesmas demandas do mercado ata o momento destacadas, é necesario que mediante o abandono ou o fracaso escolar a escola "sacrifique" 
(Fernández Enguita, 1990, 242) individuos en aras desa cantidade da man de obra descualificada requirida (Fernández Enguita, 1990, 259).

\section{Conclusións}

Tomando como referencia fundamental tanto as "competencias clave" como os "estándares de aprendizaxe" do caso, asumido como paradigmático, da LOMCE española, podemos concluír que, lonxe de procurar a formación intelectual e moral dos individuos, o actual sistema escolar —en coalición con outros dispositivos como os mass media- fomenta subrepticiamente, reproducindo determinadas relacións de poder hexemónicas, a conformación das subxectividades máis propicias para a perpetuación do propio sistema capitalista. Deste xeito, se ben debemos recoñecer, con Paulo Freire, que "enseñar exige reconocer que la educación es ideología" $(1997,120)$, cremos que o fin prioritario daquela require fomentar unhas subxectividades que sexan capaces de percibir o mundo de maneira distinta á cosmovisión hexemónica (Baceiredo, 2013, 149), de romper coa homoxeneidade (Han, 2014, 123). A educación non se pode considerar como tal se non asume a crítica, pois a propia ensinanza require a crítica (Freire, 1997, 32).

Debemos promover, así, unha nova comprensión das escolas como "comunidades vivas, sin muros, translúcidas, de participación democrática, de búsqueda intelectual, de diálogo y aprendizaje compartido, de deliberación social, de responsabilización colectiva y personal” (Pardo \& García Tobío, 2003, 81). Para garantir a liberdade persoal demandada polo neoliberalismo, en definitiva, os individuos teñen que comezar por analizar a súa propia situación, deben ser conscientes das súas eleccións, e isto non é posible sen unha formación intelectual e moral como a desenvolta, por exemplo, polos saberes humanísticos relegados hoxe fóra do currículo escolar.

\section{Bibliografía}

Almarcha, A. \& Campelo, L., "Lo que el feminismo no logró evitar: la anorexia como expresión de la deficiencia del cuerpo", Revista galegoportuguesa de Psicoloxía e Educación 4 (1999), 69-82.

Altares, G. \&Álvarez,P., “Platón, expulsadodeclase”, ElPaís, https://politica. elpais.com/politica/2015/10/02/actualidad/1443800282_346551.html, 05 de octubre del 2015 [consultado o 30/12/17]. 
Anzaldúa, R., "Infancias y adolescencias en el entramado de los procesos de subjetivación" Tramas 36 (2012), 177-208.

Ariès, P., El niño y la vida familiar en el antiguo régimen, Madrid, Taurus, 1987.

Baceiredo, R., O suxeito posmoderno: entre a estética e o consumo, Vigo, Galaxia, 2006.

Baceiredo, R., A revolución non vai ser televisada: devir imperceptible seguindo a Gilles Deleuze, Vigo, Euseino Editores, 2013.

Baudrillard, J., El sistema de los objetos, México, Siglo Veintiuno, 1988.

Bauman, Z., Modernidad líquida, Buenos Aires, Fondo de Cultura Económica, 2003.

Bernal, J. L. \& Vázquez Toledo, S., "La nueva gestión pública (NGP/NPM): El desembarco de las ideas neoliberales con la LOMCE", Témpora: Revista de historia y sociología de la educación 16 (2013), 35-58.

Ema, J. E., "Capitalismo y subjetividad. ¿Qué sujeto, qué vínculo y qué libertad?", Psicoperspectivas 8 (2009), 224-247.

Decreto 86/2015, de 25 de junio, por el que se establece el currículo de la educación secundaria obligatoria y del bachillerato en la Comunidad Autónoma de Galicia. Diario oficial de Galicia, núm. 120, 29 de junio de 2015, https://www.xunta.gal/dog/Publicados/2015/20150629/ AnuncioG0164-260615-0002_es.html [consultado o 20/01/18].

Deleuze, G., Conversaciones, Valencia, Pre-Textos, 2006.

Fernández Enguita, M., La cara oculta de la escuela: educación y trabajo en el capitalismo, Madrid, Siglo XXI, 1990.

Foucault, M., Las palabras y las cosas, Madrid, Siglo XXI, 1968.

Foucault, M., Microfísica del poder, Madrid, Ediciones de La Piqueta, 1978.

Foucault, M., Historia de la locura en la época clásica, vol. I, México, Fondo de Cultura Económica, 1979.

Foucault, M., Vigilar y castigar: nacimiento de la prisión, México, Siglo Veintiuno., 1998.

Foucault, M., El orden del discurso, México, Tusquets, 2013.

Freire, P., Pedagogía de la autonomía: saberes necesarios para la práctica educativa, Madrid, Siglo XXI, 1997.

García Pedraza, R., "Desafíos a la igualdad en el siglo XXI: dificultades y retos del modelo de escuela comprensiva", Revista Española de Educación Comparada 26 (2015), 135-152. https://doi.org/10.5944/reec.26.2015.14445 
Grosrichard, A., "El juego de Foucault”, Diwan 2 (1978), 171-202. Disponible en: http://hellowax.com/farp/wp-content/uploads/2017/06/ ElJuegoDeMichelFoucault.pdf [consultado o 22/12/17].

Gunter, H. \& Fitzgerald, T., "New Public Management and the modernization of education systems 1", Journal of Educational Administration and History 45 (2013), 213-219.

https://doi.org/10.1080/00220620.2013.822354 https://doi.org/10.1080/00220620.2013.796914 https://doi.org/10.1080/00220620.2013.768967

Han, B-C., La sociedad del cansancio., Barcelona, Herder, 2012.

Han, B-C., Psicopolitica, Barcelona, Herder, 2014.

Hayek, F., Camino de servidumbre, Madrid, Alianza, 1995.

Jameson, F., Teoría de la postmodernidad, Madrid, Trotta, 2001.

Justo Herrero, A., Postmodernidad y adolescencia: construcción de la identidad en el sujeto adolescente postmoderno, Tesis doctoral, Santiago de Compostela, Universidade de Santiago de Compostela, 2016.

Lacan, J., Seminario 16: de un otro al otro, Buenos Aires, Paidós, 2008.

Ley orgánica 8/2013, de 9 de diciembre, para la mejora de la calidad educativa. Boletín Oficial del Estado, núm. 295, 10 de diciembre de 2013, pp. 97858-97921, http://www.boe.es/boe/dias/2013/12/10/pdfs/ BOE-A-2013-12886.pdf [consultado o 23/08/17].

Mora, R., "El nacimiento de la escuela", documento no publicado, 2014. Disponible en: http://www.yumpu.es/document/view/14411711/elnacimiento-de-la-escuelareynaldo-mora-ride-inicio/7 [consultado o 23/08/17].

Orden ECD/65/2015, de 21 de enero, por la que se describen las relaciones entre las competencias, los contenidos y los criterios de evaluación de la Educación Primaria, la Educación Secundaria Obligatoria y el Bachillerato. Boletín Oficial del Estado, núm. 25, 29 de enero de 2015, pp. 6986-7003, https://www.boe.es/boe/dias/2015/01/29/pdfs/ BOE-A-2015-738.pdf [consultado o 23/08/17].

Pacheco Filho, R., "El capitalismo neoliberal y su sujeto", Teoría y crítica de la psicología 2 (2012), 113-125.

Pardo, J. C. \& García Tobío, A., "Los estragos del neoliberalismo y la Educación Pública”, Educatio siglo XXI: Revista de la Facultad de Educación 20 (2003), 39-85.

Pardo, J. C., "La lógica de las competencias para la escuela de la postmodernidad", en $\mathrm{M}^{\mathrm{a}}$. D. Fernández Tilve \& G. F. Fernández Suárez (coord.) La escuela de ayer, hoy y mañana: claves y desafíos, Madrid, Dykinson, 2016, 25-42. 
Pérez Gómez, A., "La función social y educativa de la escuela obligatoria”, Signos. Teoría y práctica de la educación 8/9 (1993), 16-27.

Poster, M., Foucault, marxismo e historia: modo de producción versus modo de información, Buenos Aires, Paidós, 1987.

RadlPhilipp, R., "Identidades de género, medios y nuevos medios tecnológicos de la comunicación", en J. García Marín (ed.) Postmodernidade e novas redes sociais, Santiago de Compostela, Universidade de Santiago de Compostela, 2012, 21-34.

Real Decreto 1105/2014, de 26 de diciembre, por el que se establece el currículo básico de la Educación Secundaria Obligatoria y del Bachillerato. Boletín Oficial del Estado, núm. 3, de 3 de enero de 2015, pp. 169546, https://www.boe.es/boe/dias/2015/01/03/pdfs/BOE-A-2015-37.pdf [consultado o 23/08/17].

Roca, M., "La subjetividad narrativa posmoderna: procesos determinantes", Revista de Literatura 67 (2005), 333-348. https://doi.org/10.3989/revliteratura.2005.v67.i134.98

Rodríguez, P. E., “¿Qué son las sociedades de control?”, Sociedad. Revista de la Facultad de Ciencias Sociales de la UBA 27 (2008), 177-192. Disponible en: http://www.sociales.uba.ar/wp-content/uploads/21.Qu\%C3\%A9-son-las-sociedades-de-control.pdf [consultado o 27/12/17].

Romano, V., La formación de la mentalidad sumisa, Barcelona, El Viejo Topo, 2007.

Ruiz de Miguel, C., "Factores familiares vinculados al bajo rendimiento", Revista Complutense de Educación 12 (2001), 81-113.

San Fabián, J. L., "La escolaridad obligatoria: transiciones y tradiciones", Cuadernos de Pedagogía 282 (1999), 25-30.

Sossa, A. \& Brange, A., "Sujeto, Foucault y América Latina: apuntes para una discusión”, Enfoques 26 (2014), 99-117.

Verger, A. \& Normand, R., "Nueva Gestión Pública y educación: elementos teóricos y conceptuales para el estudio de un modelo de reforma educativa global”, Educação \& Sociedade 36 (2015), 599-622. https://doi.org/10.1590/ES0101-73302015152619 https://doi.org/10.1590/ES0101-73302015152799 